\title{
Use of methohexital for elective intubation in neonates
}

\author{
G Naulaers, E Deloof, C Vanhole, E Kola, H Devlieger
}

\begin{abstract}
The effectiveness and safety of a short acting barbiturate, methohexital, was assessed for its use at the time of elective intubation in 18 newborn infants with severe respiratory or cardiac conditions. Evaluation included the speed of action and the degree of relaxation, sedation, and sleep in the first five minutes after administration. All newborn infants were intubated in a fully relaxed and somnolent state. In most infants recovery was completed within five minutes.

A slight to moderate oxygen saturation drop was observed during the period of intubation, especially in patients with cyanotic heart disease. The side effects of the drug were twitching and a slight drop in blood pressure.

In conclusion, methohexital seems to be a useful drug for short term anaesthesia in neonates, during which, short procedures like elective intubation can be safely performed.

(Arch Dis Child 1997;77:F61-F64)
\end{abstract}

Keywords: methohexital; intubation; anaesthesia

Intubation of a newborn infant is a difficult procedure, probably uncomfortable for the patient, and is often accompanied by transient hypoxia, acidosis, and bradycardia. In some units sedatives or even intravenous anaesthetics are administered to facilitate the procedure. Others have suggested the administration of atropine to diminish reflex bradycardia. Sedation and analgesia with midazolam, fentanyl, and morphine have been described, ${ }^{1}$ but they all have the disadvantage of prolonged action and have important side effects. Three important alternatives are intravenous anaesthetic drugs like thiopental, methohexital, and propofol. Thiopental leads to a slower recovery than methohexital. ${ }^{2}$ Propofol also has a longer action and more side effects than methohexital. ${ }^{3}$ Although methohexital was first described in $1960,{ }^{4}$ its use in infants and children was only mentioned recently. ${ }^{256}$ To our knowledge, its use has never been reported in (preterm) newborn infants. Here, we report on the effect of methohexital in terms of sedation, relaxation, sleep and cardiovascular effects in 18 newborn infants who needed an elective intubation.

\section{Methods}

We prospectively studied 18 consecutively seen infants who needed elective intubation, either to initiate mechanical ventilation because of respiratory insufficiency or postoperative ventilation, or to prevent an impending blockage of the endotracheal tube. Infants below a gestational age of 32 weeks were excluded. The 18 infants had a mean gestational age of 36.3 weeks (32-42 weeks), a mean postnatal age of 23 days (1-150 days), and a mean weight of $2588 \mathrm{~g}(1390-5000 \mathrm{~g})$ at the time of study.

All patients had cardiac and/or respiratory problems. Six patients had cyanotic congenital heart disease. Three patients had respiratory distress syndrome (RDS) with pulmonary hypertension, four patients had bronchopulmonary dysplasia (BPD), one patient had a diaphragmatic hernia, one patient a oesophageal atresia and one a cystic adenomatoid lung malformation.

All intubations were done in the neonatal intensive care unit. All patients had intravenous and arterial lines. No other anaesthetic or sedative drugs were given during the 24 hours preceding the intubation. Except for one patient who received multiple doses (three times) of methohexital, all the other patients received the drug only once.

Methohexital was given in a dose of 2.6 $\mathrm{mg} / \mathrm{kg}$ according to the study of Westrin. ${ }^{6}$ The solution was prepared by mixing $500 \mathrm{mg}$ methohexital sodium with $50 \mathrm{ml}$ physiological saline $(10 \mathrm{mg} / \mathrm{ml})$. Of this solution, $0.26 \mathrm{ml} / \mathrm{kg}$ was given intravenously. When no central venous line was available, this solution was dissolved in $1 \mathrm{ml}$ of intralipid to diminish irritation and pain during injection, according to the method proposed by Westrin. ${ }^{6}$ The drug was administered as an intravenous bolus and flushed with $1 \mathrm{ml}$ of physiological saline. Signs of distress and/or pain during injection were noted.

Before the injection of methohexital, oxygen was administered to the patient. After methohexital had been given the patient was ventilated by face mask. The intubation procedure was started as soon as the patient no longer reacted to heel rubbing or the act of inserting the nasotracheal tube. No atropine was given to the patient before the intubation. Sedation, relaxation, and sleep were recorded by one investigator who was not involved in the procedure. Observations were carried out every minute, for the first five minutes. The degree of sedation was assessed mainly as the motor response to external stimuli. As a stimulus "heel-rubbing" (rubbing the heel with a swaddle, as described by Grunau et al was used). Four degrees of reactions were defined: "Moves spontaneously," "moves when 

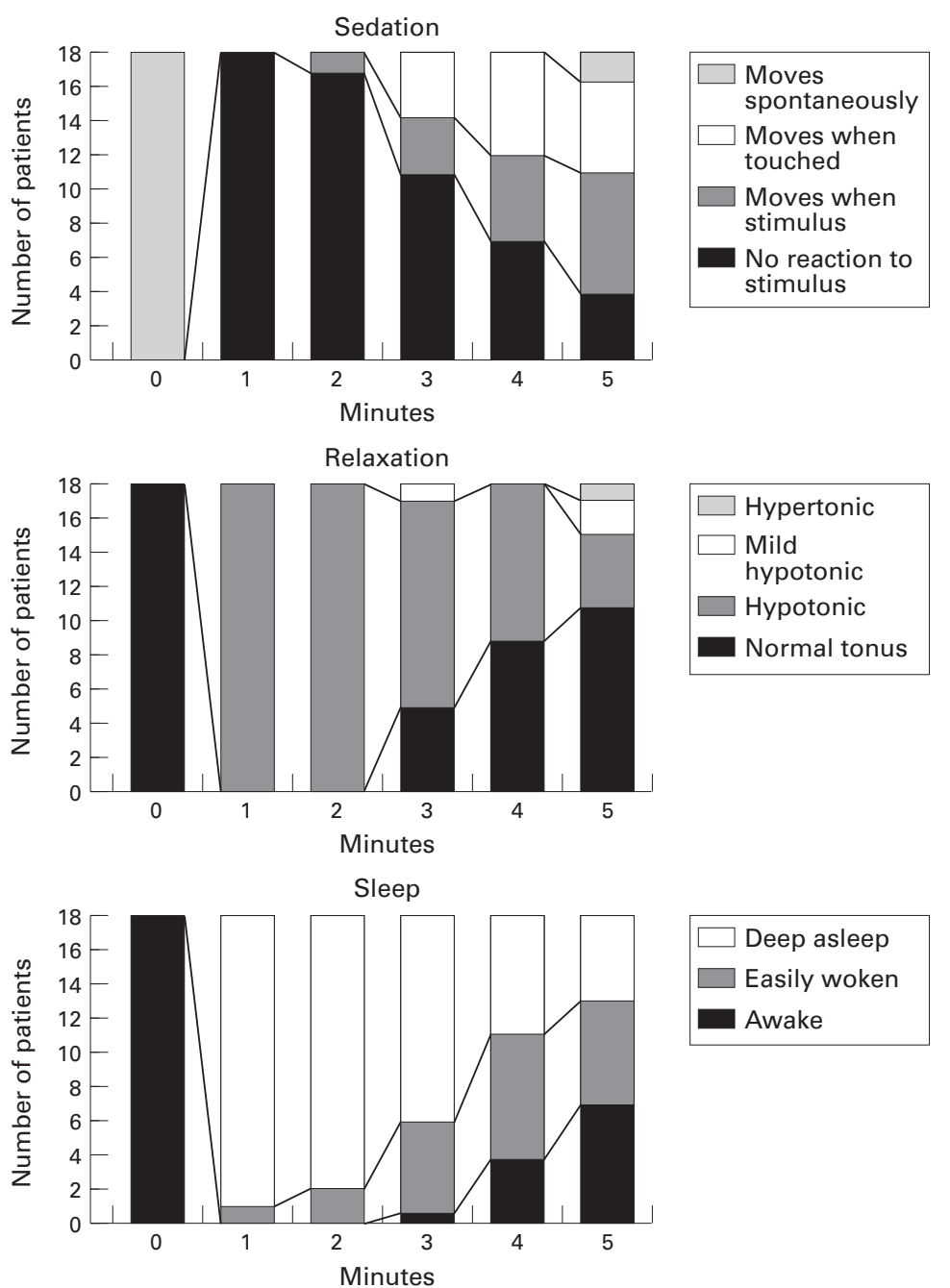

Figure 1 Effect of methohexital on sedation, relaxation, and sleep in neonates.

touched," "moves when stimulated" and "no reaction to stimulus." Relaxation was evaluated by clinical evaluation of the tone in arms and legs. We used the categories "hypotonic," "mildly hypotonic," "normal tone" and "hypertonic." Sleep was noted as "awake," easily woken," and "deep asleep." Heart rate, diastolic and systolic blood pressures, and oxygen saturation were measured using a Siemens Sirecust 3000 monitor and the values were recorded every 30 seconds for the first two minutes, every minute up to five minutes, and every five minutes thereafter, for the next half hour. The median values and the 25 th and 75 th interquartile ranges were calculated. A constant trend measurement was given by the monitor and when there was an important fall in the blood pressure, this was noted. Observations were made for hiccough, abnormal behaviour, muscle twitching, convulsions and other side effects.

\section{Results}

No redness, signs of pain, or any other problems were noted during or after the injection, when administered peripherally. In all patients the intubation procedure was initiated when the infant no longer reacted to manipu- lation. This was at a mean of 45 seconds, with an interquartile range of 20 seconds at the 25 th quartile, and at 70 seconds at the 75 th quartile. The exact time of intubation was not noted, but the infants were all intubated within two minutes.

The influence on body movements, tone, and awake/sleep state is shown in fig 1. During the first two minutes all patients were adequately sedated. Sedation was still good in $11 / 18$ patients after three minutes, while $4 / 18$ patients still did not show any reaction after five minutes. After 10 minutes all patients were moving spontaneously.

Relaxation was good during the first two minutes in all patients. After three minutes $12 / 18$ patients were still hypotonic. One patient became hypertonic after five minutes, remaining hypertonic for one minute. All patients had normal tone after eight minutes. After three minutes $12 / 18$ patients were deep asleep; 5/18 patients were still asleep after five minutes. All patients were awake after 12 minutes.

The influence of heart rate and blood pressure on oxygen saturation is shown in fig 2 . Heart rate was measured during the first 30 minutes. No serious short or long term effects on heart rate were noticed. No important change in diastolic and systolic blood pressures occurred except for a transient drop in systolic blood pressure between one and three minutes. There were no significant drops in blood pressure.

Oxygen saturation values varied considerably between 0.5 and three minutes as a result of the intubation procedure. Saturation drops of more than $10 \%$ were found in eight patients - namely, all patients with cardiac disease and all those with pulmonary hypertension. An important variance was also observed between 10 and 15 minutes when the patient was reconnected to the ventilator. When we looked at the group of patients with cyanotic heart disease, there were very important drops in saturation. Five of the six patients had a fall in oxygen saturation drop below $85 \%$ for more than 30 seconds. In the group with pulmonary disease (including the patients with pulmonary hypertension) we saw a significant drop in oxygen saturation between 30 and 90 seconds as a result of the intubation procedure. Four of the 12 patients had a saturation below $85 \%$ for more than 30 seconds. These were two patients with severe BPD and two patients with pulmonary hypertension.

The most important side effect seen was muscle twitching in two patients. The muscle twitching was similar to that seen after the administration of midazolam. Muscle twitching never lasted longer than one minute and never re-occurred subsequently. Three patients developed hiccoughs. No significant bronchospasms were encountered.

\section{Discussion}

Intubation is an invasive procedure with important effects on the respiratory and cardiovascular system. When the patient is not sedated, severe problems such as bronchospasm, pulmonary hypertension, bradycardia 
and intubation trauma can occur. Therefore, for elective intubations, we give sedation and even anaesthesia. Most sedative or analgesic drugs commonly used in neonatal care have a prolonged effect. Fentanyl and sufentanyl are known to have variable half lives. ${ }^{8}$ Furthermore, these drugs have serious side effects like chest wall rigidity, respiratory depression, delayed gastric emptying, decreased gastrointestinal motility, nausea and an increase of the common bile duct pressure. ${ }^{9-15}$ Morphine is less frequently used than fentanyl because it results in hypotension and may produce histamine release. ${ }^{16}$ Benzodiazepines are also frequently used. Midazolam has a elimination half life in neonates of 6.5 to 12 hours $^{17}{ }^{18}$ and can produce respiratory depression, hypotension, and in some patients hyperalgesia and agitation. ${ }^{19} 20$ Diazepam also leads to hypotension and respiratory depression and its half life is substantially prolonged in neonates. ${ }^{21}$ Lorazepam has an elimination half life of 10 to 20 hours and is certainly not appropriate for short time sedation. Other sedatives like chloral hydrate and phenobarbital are not potent enough to relieve discomfort and resistance to the intubation procedure.

Propofol, thiopental, and methohexital are known to be short acting anaesthetics in infants. Propofol causes prolongation of the QT-interval and this results in a higher incidence of bradycardia or junctional rhythm compared with methohexital or thiopental. ${ }^{5}$ Short acting barbiturates, especially methohexital, have recently become the focus of renewed attention for use in infants and children. Beskow et al compared methohexital with thiopental and found faster recovery after methohexital in infants aged 1 to 12 months. $^{2}$ Other reports also mention fewer cardiovascular side effects and faster recovery when methohexital is compared with thiopental..$^{22-26}$
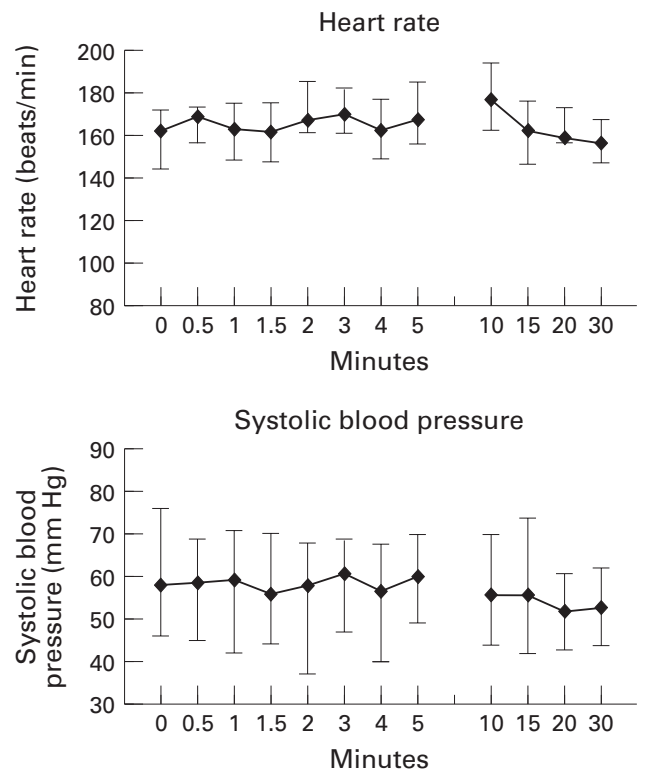

In this report the usefulness of methohexital as an adjuvant drug to facilitate intubation of preterm and full term newborn infants has been demonstrated. Good relaxation, sedation, and sleep during intubation, with a total recovery within 10 minutes, were found. Heart rate and blood pressure did not vary during the ensuing 30 minutes, despite the fact no atropine was given. ${ }^{4}$ This contrasts with other reports in older children and adults where tachycardia was found after the injection of methohexital. ${ }^{27-29}$ The drop in oxygen saturation, seen during the first three minutes, especially in cardiac patients and patients with severe BPD, can be explained by the intubation procedure.

Intubation of neonates and premature infants is still very difficult and stressful. In our study patients with severe cardiac or respiratory conditions were intubated by the attending paediatrician who was in charge of the patient. Similar studies carried out on stable patients, like an anaesthetic induction prior to minor surgery, also describe oxygen saturation drops during intubation. In two different hospitals Kong et $a l^{30}$ found that $30 \%$ of the neonates and small infants experienced desaturation of more than $5 \%$ at one or more recordings during induction. Lackcock and $\mathrm{McNicol}^{31}$ found that about $40 \%$ of the children who where aged under one year suffered a maximum fall to less than $90 \%$ saturation during induction of anaesthesia. During general anaesthesia $54 \%$ of neonates sustained a fall in saturation to $85 \%$ or less for at least 30 seconds in a group of 13 neonates reported by Schulz and colleagues. ${ }^{32}$ Taylor and Lerman ${ }^{33}$ found a decrease in saturation to less than $90 \%$ in $18 \%$ of infants aged under one year. Millar and Bisonnette ${ }^{34}$ did not find any decrease in oxygen saturations in 13 term infants where they practised an awake intubation, but their
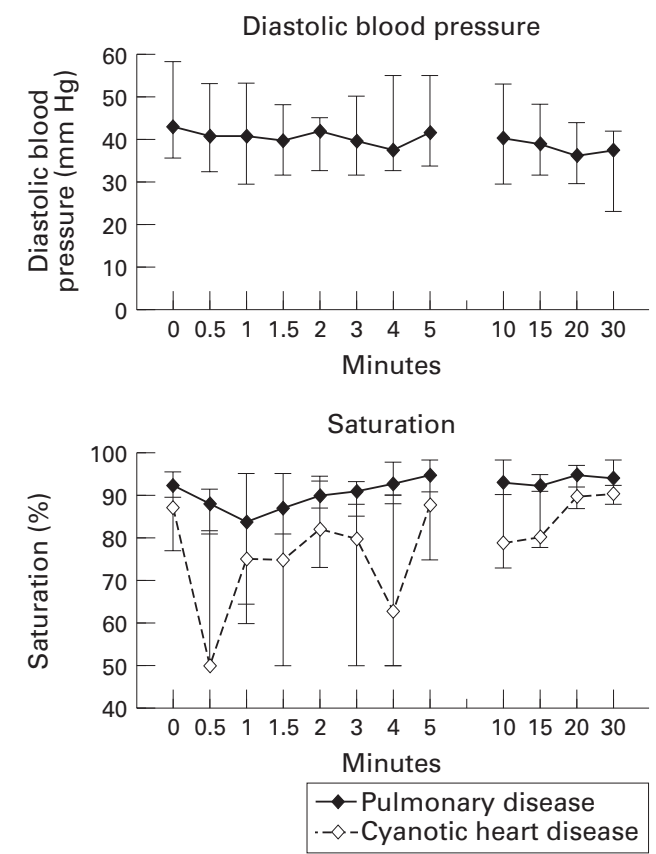

Figure 2 Median values, 25th and 75th interquartile ranges of heart rate, systolic and diastolic blood pressure and oxygen saturation before, during, and after methohexital injection. 
exclusion criteria included the presence of known intracranial, cardiovascular, or laryngeal pathology. Barrington et $a \mathrm{~B}^{35}$ also found a significant fall in transcutaneous oxygen in 20 preterm newborn infants randomly assigned to receive either atropine alone or atropine plus succinylcholine before nasotracheal intubation. All these studies were carried out in neonates without severe cardiorespiratory problems. In our study patients with cyanotic heart disease, severe BPD, and pulmonary hypertension had the most important drop in oxygen saturation. Only in the group of patients with cardiac problems was a second period of low saturation observed at the time the patient was reconnected to the ventilator.

No serious side effects were encountered. Myoclonic jerks, similar to those described with midazolam, were seen in three patients. No baby developed convulsions and all patients had a normal neurological outcome. No investigations were carried out to evaluate the effect on cerebral circulation in these neonates.

We cautiously recommend methohexital as a drug for a short induction of anaesthesia in neonates. We used it for elective intubation, but other procedures such as the insertion of a chest tube or of a deep venous catheter could also benefit from the use of this drug. The drug produces quick and short term anaesthesia without significant side effects and with a stable cardiovascular system. We must, however, await further investigations concerning ED50values for neonates and premature infants before advising the regular and/or repeated use of this drug for different procedures. The dose we used is recommended by Westrin $e t a l^{4}$ for infants, but we do not know the exact ED50-values for neonates or premature babies. The redistribution could be different, taking into account the higher percentage of extracellular fluid in this group of patients. The immaturity of cytochrome P450 in these patients will also have an important role. In our group of patients we did not see any effects after 10 minutes, but we do not know what the effect will be after repeated doses of methohexital. In the patient in whom methohexital was used on three separate occasions, no different effects were observed in subsequent administrations.

Further investigations, especially on the effect of brain circulation in preterm infants and the effect of repeated use in the same patient, must be carried out, before this drug can be used regularly in the neonatal intensive care unit. Furthermore, we think there is still a need for basic research on the effect of intubation of very sick premature and term neonates as most of the studies are done in stable patients in perfect circumstances (induction of anaesthesia for minor surgery) and not in the acute neonatal intensive care setting.

1 Truog R, Anand KJ. Management of pain in the postoperative neonate. Clin Perinatol 1989;16:61-78.

2 Beskow A, Werner O, Westrin P. Faster recovery after anesthesia in infants after intravenous induction with methohexital instead of thiopental. Anesthesiology 1995;83:976-9.

3 Saarnivaara L, Hiller A, Oikkonen M. OT-interval, heart rate and arterial pressures using propofol, thiopentone or methohexitone for induction of anaesthesia in children. Acta Anaesthesiol Scand 1993;37:419-23.

4 Taylor C, Stoelting VK. Methohexital sodium: A new ultrashort acting barbiturate. Anesthesiology 1960;21:29-34.

5 Crumrine RS, Yodlowski EH. Assessment of neuromuscular function in infants. Anesthesiology 1981;54:29-32.

6 Westrin P. Methohexital dissolved in lipid emulsion for intravenous induction of anesthesia in infants and children. Anesthesiology 1992;76:917-21.

7 Grunau RVE, Craig KD. Pain expression in neonates: facial action and cry. Pain 1987;28:395-410.

8 Gauntlett IS, Fischer DM, Hertzka RE, et al. Pharmacokinetics of fentanyl in neonatal humans and lambs : effects of age. Anesthesiology 1988;69:683-7.

9 Comstock MK, Carter JG, Moyers JR, Stevens WC. Rigid-

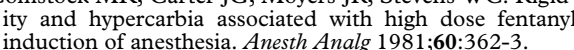

10 Mentor ML, Schwalb AJ, Lieberman RW. Rapid high-dose fentanyl induction for CABG. Anesthesiology 1980;53:S95.

11 Scamman FL. Fentanyl-O2-N2O rigidity and pulmonary compliance. Anesth Analg 1983;62:332-4.

12 Hill AB, Nahrwold ML, de Rosayro AM, et al. Prevention of rigidity during fentanyl-oxygen induction of anesthesia. Anesthesiology 1981;55:452-4.

13 Bailey PL, Wilbrink J, Zwanikken P, et al. Anesthetic induction with fentanyl. Anesth Analg 1985;64:48-53.

14 Marat I, Levron JC, Berg A, Saint-Maurice C. Effects of fentanyl on baroreceptor reflex control of heart rate in newborn infants. Anesthesiology 1988;68:717-32.

15 Friesen RH, Henry DB. Cardiovascular changes in preterm neonates receiving isoflurane, halothane, fentanyl, and ketamine. Anesthesiology 1986;64:238-42.

16 Rosow CE, Moss J, Philbin DM, Savarese JJ. Histamine release during morphine and fentanyl anesthesia. Anesthesiology 1982;56:93-6.

17 Jacqz-Aigrain E, Wood C, Robieux I. Pharmacokinetics of midazolam in critically ill neonates. Eur f Clin Pharmacol 1990;39:191-2.

18 Jacqz-Aigrain E, Daoud P, Burtin P, Mahezzi S, Beaufils F. Pharmacokinetics of midazolam during continuous infusion in critically ill neonates. Eur f Clin Pharmacol 1992; 42:329-32.

19 Burtin P, Daoud P, Jacqz-Aigrain E, et al. Hypotension with midazolam and fentanyl in the newborn. Lancet 1991; 337:1545-6.

20 Niv D, Davidovich S, Geller E, Urca G. Analgesic and hyperalgesic effects of midazolam : dependence on route of administration. Anesth Analg 1988;67:1169-73.

21 Morselli P L, Principi N, Tognoni G. Diazepam elemination in premature and full term infants, and children. $\mathcal{F}$ Perinatol 1973;1:133-41.

22 Schrum SF, Hannallah RS, Verghese PM, Welborn LG, Norden J M, Ruttiman U. Comparison of propofol and thiopental for rapid anesthesia induction in infants. Anesth Analg 1994;78:482-5.

23 Valtonen M, Iisalo E, Kanto J, Tikkanen J. Comparison between propofol and thiopentone for induction of anaesbetween propofol and thiopentone for induction
thesia in children. Anaesthesia 1988;43:696-9.

24 Hiller AU. Comparison of cardiovascular changes during anaesthesia and recovery from propofol-alfentanyl-nitrous oxide and thiopentone-halothane-nitrous oxide anaesthesia in children undergoing otolaryngological surgery. Acta Anaesthesiol Scand 1993;37:737-41.

25 Aun CS, Sung RY, O'Meara ME, Short TG, Oh TE. Cardiovascular effects of i.v. induction in children:
comparison between propofol and thiopenthone. $B r \mathscr{J}$ Anaesth 1993;70:647-53.

26 Runcie CJ, Mackenzie SJ, Arthur DS, Morton NS. Comparison of recovery from anaesthesia induced in children with either propofol or thiopentone. Br $\mathcal{F}$ Anaesth 1993;70: 192-5.

27 McCollum JS, Dundee JW. Comparison of induction characteristics of four intravenous anaesthetic agents. Anaesthesia 1986;41:998-1000.

28 Raeder JC, Misvaer G. Comparison of propofol induction with thiopentone or methohexitone in short outpatient general anaesthesia. Acta Anaesthesiol Scand 1988;32:60713

29 Gold MI, Abraham EC, Herrrington C. A controlled investigation of propofol, thiopentone and methohexitone. Can f Anaesth 1987;34:478-83.

30 Kong AS, Brennan L, Morgan-Hughes J. An audit of induction of anaesthesia in neonates and small infants using pulse oximetry. Anaesthesia 1992;47:896-99.

31 Laycock GJA, McNicoll LR. Hypoxaemia during induction of anaesthesia - an audit of children who underwent of anaesthesia - an audit of children who underwent general anaesth

32 Schulz C, Lenz G, Madee S, Schulze M. Frequency of hypoxic episodes during general anaesthesia in children. Cahiers d'Anesthesiologie (Paris) 1989;37:403-7.

33 Taylor RH, Lerman J. Induction, maintenance and recovery characteristics of desflurane in infants and children. Can $\mathcal{F}$ Anaesth 1992;39:6-13.

34 Millar C, Bissonnette B. Awake intubation increases intracranial pressure without affecting cerebral blood flow velocity in infants. Can $\mathcal{F}$ Anaesth 1994;41:281-7.

35 Barrington KJ, Finer NN, Etches PC. Succinylcholine and atropine for premedication of the newborn infant before nasotracheal intubation: A randomized, controlled trial. Crit Care Med 1989;17:1293-6. 